\title{
Knowledge Infrastructures: Part III
}

\author{
Helena Karasti \\ Department of People and Technology, Roskilde University, Denmark / hkarasti@ruc.dk \\ Information Systems, Luleå University of Technology, Sweden / helena.karasti@ltu.se \\ INTERACT, University of Oulu, Finland / helena.karasti@oulu.fi
}

\author{
Florence Millerand \\ Department of Public and Social Communication, University of Quebec at Montreal, Canada I \\ millerand.florence@uqam.ca
}

Christine M. Hine

Department of Sociology, University of Surrey, UK / c.hine@surrey.ac.uk

\author{
Geoffrey C. Bowker \\ Department of Informatics, University of Irvine, CA, USA / gbowker@uci.edu
}

This issue of Science and Technology Studies constitutes the third instalment of the special issue on Knowledge Infrastructures. Our initial call to take stock of existing research in this topic area across STS produced a high level of response and so the "special issue" will ultimately extend over the entire four issues of volume 29 of the Science \& Technology Studies journal for the year 2016.

In the previous two issues of Science \& Technology Studies, we have presented seven substantively very different studies. The first instalment presented an initial batch of three studies: Wyatt et al. (2016) explored the treatment of controversy within the production of the Wikipedia entry relating to schizophrenia genetics; Parmiggiani and Monteiro (2016) examined the production of infrastructures relating to the monitoring of environmental risk in off shore oil and gas operations; and Boyce (2016) analysed the work of connecting infrastructures for public health surveillance. The second part of the special issue put forward an further set of three articles and a discussion paper: Fukushima (2016) discussed value oscillation in knowledge infrastructures through two case studies in Japan's drug discovery; Jalbert (2016) analysed the issues of power and empowerment in environmental monitoring infrastructures for citizen science in the context of hydraulic fracturing; Dagiral \& Peerbaye (2016) investigated the ways infrastructural issues come to matter in the social worlds of rare diseases; and Shankar et al.'s discussion paper (2016) shed new light on the role social science data archives have played as infrastructures in the development of social science disciplines.

The four articles presented in this third instalment of the special issue continue to present very different studies. The four book reviews also 
appearing in this instalment further expand the substantive diversity and demonstrate the disciplinary breadth of interest in knowledge infrastructure studies.

\section{Articles in This Third Part of the Special Issue}

The special issue opens with an article by $\mathrm{Yu}$ Wei Lin, Jo Bates and Paula Goodale on crowdsourcing weather data. The "Co-observing the Weather, Co-predicting the Climate: Human Factors in Building Infrastructures for Crowdsourced Data" paper addresses a core issue for a number of sciences moving forward: how to build citizen science into their knowledge infrastructure. For the observational sciences (for example, Galaxy Zoo) and the digital humanities (the Bentham project, for example), there are huge benefits to building citizens into both the data infrastructures (highlighted in this paper) and through this process into the knowledge infrastructures being constructed. The authors of this article produced an ethnographic analysis of three central projects: the Weather Observation Website and the (presumably doubly ironically named) Weather Underground, which are about collecting data from local weather stations; and the Old Weather project, which like the Bentham project is seeking to crowdsource transcriptions of old weather logs from naval vessels and other sources. The authors produce a nuanced description of the work of socialization, embodiment, engagement with professionals (how often to calibrate instruments, for example), development of tacit knowledge and trust-building needed to make the emergent infrastructure work.

This is a valuable contribution to our understanding of the issue of the division of cognitive labor within the crowdsourced science: the citizen scientists are never just unskilled labor paving the way for the real scientific work. They need to learn about professional standards and how to engage with them; they need to develop new skills (e.g. transcribing US naval logs, with a new vocabulary to decipher) and so forth. Further, they need to develop modalities for offering and eliciting skills and tips to their respective websites. Finally, there is a degree of bodily and emotional engagement, which accompanies their work.
While many of the articles included under the umbrella of knowledge infrastructures have involved information technologies, our focus also extends to other forms of technology used to collate and aggregate knowledge. The theoretical interests of STS, in any case, do not see an infrastructure as the upshot of a particular technology in itself, but recognise that infrastructures are built out of configurations of technologies, people and institutions. In the second article "Taxonomic Government: Ecuador's National Herbarium and the Institution of Biodiversity, 1986 - 1996" we turn to a very different incarnation of the knowledge infrastructure, in the herbarium, and yet find that many of our existing theoretical concepts for understanding IT-enabled infrastructures still apply. This article explores the idea that a knowledge infrastructure can amount to a form of government, drawing on the Foucauldian notion of governmentality and highlighting the performativity of infrastructure work. Peter Taber describes the emergence of the National Herbarium in Ecuador as the upshot of a specific conjunction of biological expertise, the state and foreign finance, spanning public and private institutions and involving some unexpected alignments of interests between taxonomists and the oil industry.

The herbarium at the time Taber describes was built upon a conceptualisation of the value of knowing what species existed where and consequently acted as an infrastructure that rendered biodiversity in a particular form as a governable object. The knowledge infrastructure of the herbarium offers a basis for decisions to be taken on prioritisation of conservation interventions. In the time period that Taber describes a shift occurred in the notions of value surrounding the plants of Ecuador, from a substantive approach based on the economic valuation of plants towards a spatial approach that mapped species by locations and enacted biodiversity as an object of prioritisation in its own right. The logic of spatial prioritisation was built into the National Herbarium at this time though the collection of identified specimens mapped to a finer scale of location than had previously been considered. The fieldwork that produced this data entailed specimen collection in very challenging terrain, and biologists working in the field consequently 
moved from an opportunistic association with tree felling for oil drilling into a much closer collaborative relationship that tied knowledge of biodiversity tightly to the activities of the oil industry.

This paper therefore offers a distinctive perspective on the performativity of knowledge infrastructures by coupling detailed investigation of the expertise and alliances that enable the infrastructure with a focus on the specific forms of knowledge that the infrastructure embeds (including an understanding of how they could have been otherwise) and a focus on what it is that the infrastructure achieves in terms of the actions that it makes available. The focus on governmentality gives us an insight into the highly consequential nature of knowledge infrastructures as political tools and offers resources for unpacking some of the complex loops of feedback between the forms of knowledge that an infrastructure embeds and the various forms of action that feed into and stem from the set of values that the infrastructure enacts.

The paper "Promises that Matter: Reconfiguring Ecology in the Ecotrons" documents a reconfiguration of ecology's scientific and social missions through an analysis of large-scale research infrastructures called 'ecotrons'. Ecotrons are the latest incarnation of infrastructures in a genealogy of artificial biospheres; they are large instruments designed to produce experimentally valid knowledge through the controlled manipulation of closed, artificial ecosystems. They enable the live simulation of the environmental conditions anticipated in, for instance, global warming scenarios. Céline Granjou and Jeremy Walker conducted a study of two ecotrons recently-built in France that are the first ecological facilities sponsored by the Très Grandes Infrastructures de Recherche (TGIR) unit of the National Centre for Scientific Research (CNRS). The authors drew from interviews and exchanges with key researchers engaged in the conception and construction of the ecotrons as well as analysis of institutional documents and scientific literature presenting results of ecotron-based research.

Granjou and Walker consider ecotrons as sites for the elaboration and re-alignment of narratives of justification that embody important promises regarding the scientific status and social role of ecology. They propose thinking of ecotrons as "promissory and anticipatory infrastructures" with the potential to federate a wide community of ecologists around political narratives and shared research agendas. While ecologists have long struggled to get the scientific status of their discipline recognized, the anthropogenic changes that societies face today open new opportunities for ecology to reaffirm its promise both in terms of scientific contribution and practical relevance, and the ecotrons are seen to play a key role in this context. As the detailed account provided by the authors shows, ecotrons are an infrastructure of promise that materialize a profound reconfiguration of ecology's practices and wider civilizational narratives. What ecotrons materialize in particular is the promissory vocation of ecology to secure the resilience of the vital ecosystem of the planet. The paper ably demonstrates that ecology's infrastructures and futures are coproduced in the same movement. Ecotrons are integral to the rise of functional ecology, they encapsulate an ambition to make ecology a 'hard' science and present themselves as an emblematic 'Big Ecology' infrastructure.

One important contribution of the paper is the attention given to the role played by objects, infrastructures and materialities in stabilizing scientific promises, while studies of scientific promises have often focused on the role of speeches or the importance of politico-scientific leaders. Granjou and Walker show that it is a mistake to think of narratives and promises on one side, and passive materialities waiting for meanings on the other side. Instead, infrastructures like ecotrons materialize, combine and align promises that, in this case reconfigure ecology into a hard, anticipatory and engineering science. Their study invites us to pay more attention to the role of material objects and infrastructures in the elaboration of scientific promises and visions.

The final article "Of Blooming Flowers and Multiple Sockets: The Role of Metaphors in the Politics of Infrastructural Work" published in this third issue was initially submitted to Science \& Technology Studies as an open call manuscript. It is, however, published as part of the Knowledge Infrastructures special issue, as its focus on the development and maintenance of information 
infrastructure complements the kinds of infrastructural work and topic areas covered by the other articles. More specifically, Marcello Aspria, Marleen de Mul, Samantha Adams, and Roland Bal explore the role of two metaphors for innovation and infrastructure integration in the development of a regional patient portal in the Netherlands. In the development project the 'blooming flowers' refers to third party e-Health initiatives and the 'multiple sockets' to the portal.

The authors' premise is that metaphors have real consequences for agenda setting and decision-making; metaphors are viewed as operationalizations of sociotechnical imaginaries. The authors explore empirically how metaphors were enacted during the early stages of the project, and how this affected the development of the portal. The authors analyze the role of metaphors in defining the organizational, technical and economic boundaries of the e-Heath platform, and in endorsing the portal as an independent, non-partisan attribute in a newly envisioned technical, economic and social infrastructure for the region. The authors focus on the generative character of metaphors and argue that they are constitutive elements of information infrastructures. Metaphors become part and parcel of a recursive process of ontological constitution: elements that help to construe their ontological status and their imagined social order, and that are perpetuated and shaped by that order at the same time. While the two metaphors in the study helped to make imaginaries of 'integrated' and 'personalized' health care more definite, cognizable, and classifiable, they also concealed the politics of infrastructural work. Rather than acting simply as heuristic devices, these metaphors "act as forceful 'actors"' that become deeply engrained in the project's imaginary. While they contributed to the prescription of futures and agendas for the platform, they at the same time drew attention away from the human work required in developing and maintaining infrastructures, and from questions about the relation between infrastructures and their users.

Aspiria et al. also argue that 'engaged participatory research', as they call their research approach, can contribute to redirecting the gaze onto sociotechnical and political complexities, and to raising timely questions about the implications of imaginaries that bypass the materiality and politics of infrastructure. They point out that the act of 'spelling out' metaphors can open up a space for new imaginaries and alternative strategies. With this study they contribute to existing knowledge about infrastructural work, and specifically to a renewal of the interest among STS scholars in the role of discursive attributes in information infrastructures.

\section{Reflections and Emerging Themes}

In the previous two editorials we started to discuss themes that we have identified in the presented articles. In addition to the concerns with scale, invisibility, tension, uncertainty and accountability identified within the first batch of articles (Karasti et al., 2016a), the second issue briefly discussed a methodological issue of infrastructural inversion, and considered knowledge infrastructures as performative of the knowledge produced and as core sites of political action bringing forth concerns with power, marginalization and values (Karasti et al., 2016b). These themes continue to echo also across the four pieces presented in this third instalment of the special issue on knowledge infrastructures. In the following we briefly draw together two additional themes that emerge at this stage, temporality and labor.

Temporality emerges as a significant theme across this issue, both methodologically speaking, in terms of the varying orientations of STS researchers to the work of infrastructuring across differing time frames, and also substantively in terms of temporal issues that participants attend to and reconcile within their infrastructuring work. As Bowker (2015) points out, infrastructures have a complex temporality that often entails a messy developmental story with no defined end point. Unpicking this temporality can be a considerable challenge to the analyst, but also an illuminating and fruitful exercise. In terms of methodology the papers in this issue divide between retrospective accounts that offer a long view of infrastructuring over time and accounts based on real-time engagement with infrastructure projects in the making. Taber takes a historical perspective built upon archival work and retrospective interviews 
to explore the development of Ecuador's National Herbarium and its role in a changing approach to the valuing of biological resources. The retrospective nature of the study allows Taber to build a picture of change through time and by doing so to construct an argument about the contingent nature of the infrastructural arrangements that prevail across the time period. He demonstrates, ultimately, that the taken-for-granted status of biodiversity measured via particular forms of species inventory was arrived at through a series of practical steps and conceptual shifts that could have been otherwise. In this paper, as in the paper by Shankar et al. (2016) in the previous issue, the virtues of a historical perspective on infrastructuring are made clear, when the long view offered by a historical approach to research is coupled with a set of STS sensitivities to the heterogeneous, contingent and consequential nature of infrastructuring work. In similar style, albeit across a somewhat shorter time frame, Lin et al. adopt a framework of "following" to capture "value-making and value-changing processes, and dynamics of components, actors, rules, and relations in the infrastructure". The temporal framing of the study permits certain kinds of claim about emergence, contingency and consequences in knowledge infrastructures.

By contrast, other papers in the issue (and indeed many STS studies of knowledge infrastructure) tend to focus on real-time engagement of the researcher with the everyday work of infrastructuring. Here temporality emerges as an analytic theme when researchers recognise the significance of the different temporal frames that participants in knowledge infrastructure projects work orient to in their everyday work, uncovering themes that resonate with Steinhardt and Jackson's (2015) focus on the "anticipation work" that infrastructuring involves. Granjou and Walker explore ecotrons as a promissory infrastructure that attempts to materialise an envisioned future science and thus to secure the status of ecology as a respected science and basis for policy formation. Aspria et al. describe participants in the development of an online health portal as they engage in agenda-setting and making of decisions -activities that define current actions but also, as agendas always do, involve planning, anticipating and predicting the future. The paper unravels the complex sets of present and future concerns that animate the production of plans through a specific focus on metaphors that participants use to depict their goals and that, as the authors suggest, shape the expectations placed upon the project. These papers demonstrate the purchase offered by a detailed engagement with the present work of infrastructuring as it builds in attention to other time scales, rendering past and future present in the here and now. Such work builds on and enriches the existing STS perspectives on the significance of temporality in infrastructuring (Edwards et al., 2009) including notions of "infrastructure time" (Karasti et al., 2010) and the "long now" of infrastructure work (Ribes \& Finholt, 2009). Historical and real-time approaches yield distinctive analytic purchase and, taken together, attest to the importance of methodological diversity, in temporal terms, across the array of STS engagements with knowledge infrastructures.

A second theme which emerges across these articles is that of labor. Just as in the wider economy, labor is being configured differently in the new knowledge infrastructures. Indeed the parallels are strong. Increasingly, academic labor is becoming that strange mix of a largely rhetorical entrepreneurialism wrapped around a reality of unprotected bit work. These articles explore the issue of labor in rich ways. Lin et al. point to some of the emerging possibilities for reconfiguring the academic labor environment. There is no need to cleave to the ivory tower model of knowledge as that which is performed within universities a creaky model (under challenge since the late nineteenth century with the rise of research laboratories in the chemical and then the electrical industries). Rather, citizen scientists can make genuine contributions to scientific work. Some citizen science projects - for example the early Galaxy Zoo - had the citizens doing piece work rather on the Amazon Mechanical Turk model: making the work as simple and automatic as possible (a recollection of the women 'computers' in Hubbles' laboratory who mapped the skies in the early twentieth century - itself an echo of Prony's intellectual division of labor for producing logarithms, hailed by Charles Babbage as a major breakthrough for humanity). Lin et al. rightly 
claim that the work their citizen scientists are doing is highly skilled. The struggle for the soul of an academic enterprise now is partly about how to recognize and compensate fairly that work.

Granjou and Walker's paper looks at the labor involved into bringing 'nature' into the laboratory in ecosystem science. They analyze the emergent anticipatory infrastructure in terms of a fusion of research scientific agendas and geoengineering solutions to climate change and related issues through the reification of the concept of ecosystem services in the infrastructure. We are reminded - as with Antonia Walford's (2012) work - of the often invisible labor it takes to bring the world into the computer. It takes vast physical installations such as the ecotrons in France or the BioSphere projects in the States to make all things be equal enough to be countable and actionable. They describe the scientists working on these projects as being moved into a modality of pre-emptive security. This is a second kind of reconfiguration of academic labor from Lin et al.'s; the latter looked to democratizing science (with concerns about equity), the former to operationalizing science (with concerns about a new division of intellectual labor tying science to the invasive security state). Taber observes a similar move: in his case the integration of systematics research into the operations of the oil companies seeking to garner Ecuador's oil reserves. The botanists gain access to samples through use of the equipment of the companies: the price to be paid, as with Granjou and Walker, is to integrate their work into commercial and state interests. While it is true that scientific work has been closely tied to the interests of the State (despite the misleading image of the nineteenth century 'gentleman amateur' funding their own research), these new kinds of tighter integration both change the labor of doing scientific research by integrating it into the infrastructure of the neoliberal state: the very same specter that haunts Lin et al.'s work. Whilst the theme of labor is lighter in Aspria et al.'s paper, the two metaphors they discuss are integrally about working imaginaries and labor ecologies. Again, the question arises of the modalities through which new forms of knowledge work are adopted: as they point out, the metaphors used (the blooming flowers and the multiple sockets) are performative of different kinds of work organization.

Issues of labor are coming to the fore in discussions of the new kind of workforces we are creating (Uber, Airbnb) and the role of new modes of 'artificial intelligence' (supplanting jobs through automation, Amazon Mechanical Turk). It is natural that these same issues are expressed in the new forms of knowledge infrastructure we are building, which endeavor to integrate scientific labor into this more general movement.

\section{Book Reviews in This Third Part of the Special Issue}

In this issue the book reviews have been commissioned by the editors of the special issue on knowledge infrastructures in order to enable us to broaden our scope beyond journal articles and to indicate the broader intellectual context within which STS approaches to knowledge infrastructures have arisen in recent years. The four books (Kleiner et al., 2013; Wouters et al., 2013; Mongili \& Pellegrino, 2014; Meyer \& Schroeder, $2015)$ reviewed for this issue were selected from a torrent of publications on new forms of knowledge infrastructure. Taken together, the reviews surface the commonalities across this emergent domain. Yrjö Engeström (1990) argues that 'when is a tool?' is a better question than 'what is a tool?' - the latter is essentializing, the former situated. A theoretical concept such as knowledge infrastructures (KIs) is only useful to the extent that and at the moment when it can be used to characterise an emergent phenomenon it terms of a received body of literature. Each of these books - while not necessarily using the term "knowledge infrastructure", demonstrates the value of this approach. Each text, as the reviewers identify, adds something to our understanding of the concept. Across the four volumes we encounter a rich array of new case studies of infrastructures that arise within and enable knowledge work across and beyond academic disciplines. These texts also broaden the scope of the voices involved in commentary upon the aspirations and experiences of knowledge infrastructures. They include an array of authors both from STS and from participants within some of the projects under evaluation and 
target a variety of audiences from various disciplines and policy-making communities.

\section{The Fourth and Last Part of the Special Issue}

In the fourth and last instalment of the knowledge infrastructures special issue, in addition to presenting the remaining successful submissions, we will step back to review the identified themes across the full collection of papers. We will aim at that point to draw together some themes concerning the current state of understanding of knowledge infrastructures from the viewpoint of STS, to provide a basis from which to evaluate the distinctive contribution that the theoretical resources of STS are making within this territory, and to chart new directions for the study of infrastructures for research and knowledge production. This kind of assessment of the state of the field was anticipated in the announcement of the special issue and is facilitated by the rich and diverse set of contributions represented across the four instalments. 


\section{References}

Bowker GC (2015) Temporality: Theorizing the Contemporary. Cultural Anthropology. September 24, 2015. Avalaible at: https://culanth.org/fieldsights/723-temporality (accessed: 22.8.2016).

Boyce AM (2016) Outbreaks and the Management of 'Second-Order Friction': Repurposing Materials and Data From the Health Care and Food Systems for Public Health Surveillance. Science \& Technology Studies 29(1): 52-69.

Dagiral É \& Peerbaye A (2016) Making Knowledge in Boundary Infrastructures: Inside and Beyond a Database for Rare Diseases. Science \& Technology Studies 29(3): 44-61.

Edwards PN, Bowker GC, Jackson SJ, \& Williams R (2009) Introduction: An Agenda for Infrastructure Studies. Journal of the Association for Information Systems 10(5): 364-374.

Engeström Y (1990) Learning, Working and Imagining: Twelve Studies in Activity Theory. Orienta Consulting, Helsinki.

Fukushima M (2016) Value Oscillation in Knowledge Infrastructure: Observing its Dynamic in Japan's Drug Discovery Pipeline. Science \& Technology Studies 29(3): 7-25.

Jalbert K (2016) Building Knowledge Infrastructures for Empowerment: A Study of Grassroots Water Monitoring Networks in the Marcellus Shale. Science \& Technology Studies 29(3): 26-43.

Karasti H, Baker KS, \& Millerand F (2010) Infrastructure Time: Long-Term Matters in Collaborative Development. Computer Supported Cooperative Work - The Journal of Collaborative Computing and Work Practices 19(3-4): 377-415.

Karasti H, Millerand F, Hine CM, \& Bowker GC (2016a) Knowledge infrastructures: Part I. Science \& Technology Studies 29(1): 2-12.

Karasti H, Millerand F, Hine CM, \& Bowker GC (2016b) Knowledge infrastructures: Part II. Science \& Technology Studies 29(3): 2-6.

Kleiner B, Renschler I, Wernli B, Farago P, \& Joye D (eds) (2013) Understanding Research Infrastructures in the Social Sciences. Zurich: Seismo.

Meyer ET \& Schroeder R (2015) Knowledge Machines: Digital Transformations of the Sciences and Humanities. The MIT Press.

Mongili A \& Pellegrino G (eds) (2014) Information Infrastructure(s): Boundaries, Ecologies, Multiplicity. Newcastle: Cambridge Scholars Publishing.

Parmiggiani E \& Monteiro E (2016) A Measure of 'Environmental Happiness': Infrastructuring Environmental Risk in Oil and Gas Offshore Operations. Science \& Technology Studies 29(1): 30-51.

Ribes D \& Finholt T (2009) The Long Now of Technology Infrastructure: Articulating Tensions in Development. Journal of the Association for Information Systems 10(5): 375-398.

Shankar K, Eschenfelder KR, \& Downey G (2016) Studying the History of Social Science Data Archives as Knowledge Infrastructure. Science \& Technology Studies 29(3): 62-73.

Steinhardt SB \& Jackson SJ (2015) Anticipation Work: Cultivating Vision in Collective Practice. In Proceedings of the 18th ACM Conference on Computer Supported Cooperative Work \& Social Computing, Vancouver, BC, Canada, 14-18 March, 2015: 443-453. ACM, New York, NY, USA.

Walford A (2012) Data Moves: Taking Amazonian Climate Science Seriously. Cambridge Anthropology 30(2): 101-117.

Wouters P, Beaulieu A, Scharnhorst A, \& Wyatt S (2013) Virtual Knowledge: Experimenting in the Humanities and the Social Sciences. The MIT Press.

Wyatt S, Harris A, \& Kelly SE (2016) Controversy goes online: Schizophrenia genetics on Wikipedia. Science \& Technology Studies 29(1): 13-29. 